Results The failure modes that show higher benefits in risk mitigation are the wrong drug and wrong dosage with a PRI decrease of $80 \%$ (from 50 to 10). Indeed the redundant controls (vision system, scale, photocells) on the loaded vials guarantee the compounding of the right drug. In addition, the drug is dosed with a calibrated syringe pump and independently verified with the scale. The other failure modes reported a risk reduction of $50 \%$ and on the whole the total PRI passes from 186 in case of the manual activity to 63 for the robotic one.

Conclusions The FMECA analysis shows an overall reduction of the PRIs of over $66 \%$ with the robotic compounding with respect to the manual production. Automation not only decreases the occurrence of dangerous events thanks to the complete control of every single step of the compounding process, but also develops an error detection system through independent verification processes.

No conflict of interest.

\section{TCH-038 SHORTAGE OF STERILE CALCIUM GLUCONATE STOCK SOLUTION FOR PARENTERAL NUTRITION: WHAT IS THE ALTERNATIVE AND HOW MUCH DOES IT COST?}

doi:10.1136/ejhpharm-2013-000276.229

'V Siorat, 'S Serrano, ${ }^{1 P}$ Jorret, ${ }^{1 P}$ Vaconsin, ${ }^{2} \mathrm{~F}$ Brion, 'T Storme, 'M Perrinet. 'AP-HP (Hôpital Robert Debré), Pharmacy, Paris, France; ${ }^{2}$ Univ Paris Descartes, Clinical Pharmacy, Paris, France

Background The Total Parenteral Nutrition (TPN) production facility of our children's hospital produces around 20,000 units per year with 2 Baxa EM2400 compounders. In June 2012, a shortage of the calcium source $(10 \%$ sterile solution of calcium gluconate in $500 \mathrm{~mL}$ bottles) occurred. To overcome this problem, we first tried to import an alternative source but the administrative delay was too long. The only sources available within a month were $10 \mathrm{~mL}$ plastic or glass ampoules. The estimated consumption was around 300 ampoules per production day. To maintain efficiency and safety in the TPN facility, it was decided to produce calcium gluconate bags from $10 \mathrm{~mL}$ ampoules by sterilising filtration to maintain the safety of preparation.

Purpose To evaluate the additional cost incurred by setting up this production and the increased time required.

Materials and Methods The pharmacy prepared calcium gluconate bags $(250 \mathrm{~mL})$ from plastic ampoules after filtration $(0.22 \mu \mathrm{m}$ philtres (Sterivex Millipore), using a Repeater Pump (Baxter), in a laminar air flow cabinet. The cost of setting up a new procedure and of the compounding was evaluated in different categories (materials, checking, staff).

Results 228 bags were produced during the 20 days on which we could not obtain the $500 \mathrm{~mL}$ bottles (19 batches of 12 bags).

The cost of one $250 \mathrm{~mL}$ compounded bag was $€ 44.23$ (materials: 25.5, checking: $€ 5.73$, staff: $€ 13$ ). In addition, developing the system cost $€ 4,237.72$. The overall additional cost was therefore $€ 155.22 / \mathrm{L}$.

Conclusions Despite a major additional cost, compounding calcium gluconate bags has ensured the continued production of TPN. From a risk assessment point of view, identification of several suppliers and increasing our stocks of the raw materials would make out-of-stock situations easier to manage in future.

No conflict of interest.

\section{TCH-039 SIX SIGMA IN HEALTHCARE: AN APPLICATION IN THE MONITORING OF ALBUMIN}

doi:10.1136/ejhpharm-2013-000276.230

'F Cimo, 'P Marrone, 2R Citati. 'ARNAS Civico Hospital, Pharmacy Operative Unity, Palermo, Italy; ${ }^{2}$ University of Palermo, Engineering department, Palermo, Italy
Background The high off-label use of albumin persuaded the pharmacy to introduce a request form that uses the internationals guidelines to assess whether the use of albumin is appropriate. This has resulted in a clear reduction in the costs.

Purpose To monitor the wards using six sigma methodology (a statistical concept that measures a process in terms of defects); to ensure that all procedures have been followed correctly.

Materials and Methods 696 forms for albumin prescriptions coming from 26 wards (August to December 2011) were analysed using Minitab software, which cheques the frequency of the best correct requests (type 1), partially correct requests (type 2) and incorrect requests (type 3 ). For each ward the $\beta$ coefficient was used to connect the relationship between the ward and their requests. The wards were grouped into 4 ranges on confidence intervals for the odds ratio (OR) of a width equal to 0.3 called A,B,C,D and then a final logistic regression analysis was made.

Results The analysis showed that group A was the most efficient in terms of probability of obtaining better results, followed by groups D (OR 0.36), C (OR 0.19) and B (OR 0.09). The total number of requests received was: $43 \%$ type 1 (299/696); 26\% type 2 (181/696); 31\% type 3 (216/696). Group B showed the worst result with $51 \%$ type 3 requests (58\% of the total requests for type 3 ). Using six sigma we have achieved a cost saving of about $€ 15,000$.

Conclusions The results encourage us to apply this methodology to other fields.

No conflict of interest.

\section{TCH-040 STABILITY OF FROZEN CEFTAZIDIME SOLUTION IN POLYPROPYLENE SYRINGES FOR INTRAVITREAL INJECTION}

doi:10.1136/ejhpharm-2013-000276.231

J Vigneron, A Daul, N Sobalak, H Zenier, I May, B Demoré. Centre Hospitalier Universitaire de Brabois, Pharmacy, Vandoeuvre, France

Background Ceftazidime is used for the treatment of endophthalmitis by intravitreal injection. For this emergency treatment, the syringes must be available immediately in the pharmacy. The stability at $2-8^{\circ} \mathrm{C}$ is limited and does not allow batch production.

Purpose To study the stability of ready-to-use ceftazidime solution at $20 \mathrm{mg} / \mathrm{mL}$ in $0.9 \%$ sodium chloride in polypropylene syringes after storage at $-20^{\circ} \mathrm{C}$, to allow preparation in advance.

Materials and Methods We used the High Performance Liquid Chromatography method published by Abdel Hamid ME et al, Farmaco 1998; 53: 132-138.

The analytical conditions were: Column C18 $5 \mu 200 \times 4.6 \mathrm{~mm}$. Mobile phase (ammonium acetate buffer $0.1 \mathrm{M} \mathrm{pH} 7.5$ /acetonitrile 90/10), flow rate: $1 \mathrm{~mL} / \mathrm{mn}$, wavelength: $256 \mathrm{~nm}$.

The HPLC method was validated according to $\mathrm{ICH}$ guidelines (linearity, repeatability, stability-indicating capability).

Syringes were stored at $-20^{\circ} \mathrm{C}$ and $4^{\circ} \mathrm{C}$ to compare with the literature data.

Results Stability was defined according to ICH guideline Q1A: above $95 \%$ of the initial concentration of ceftazidime and concentration of degradation products less than $2 \%$. After storage at $4^{\circ} \mathrm{C}$ the ceftazidime concentration fell under $90 \%$ after 3 weeks and there was $65 \%$ of the initial concentration after 90 days.

The ceftazidime solution at $20 \mathrm{mg} / \mathrm{mL}$ was stable for 3 months at $-20^{\circ} \mathrm{C}$ with more than $96 \%$ of the initial concentration and degradation products under $0.8 \%$.

Conclusions Ceftazidime $20 \mathrm{mg} / \mathrm{mL}$ in $0.9 \%$ sodium chloride was stable for 3 months at $-20^{\circ} \mathrm{C}$. This allows batch preparation in advance and the immediate availability of the syringes to treat patients.

No conflict of interest. 